\title{
Efficiency of ten populations of Schizaphis graminum (Rondani) in the transmission of barley yellow dwarf virus-PAV (BYDV-PAV) in Iran
}

\author{
Ali Mirshekar ${ }^{1 *}$, Gholam Reza Rasoulian² and Gholam Hossein Mosahebi ${ }^{2}$ \\ ${ }^{1}$ Department of Plant Protection, Faculty of Agriculture, University of Zabol, Zabol, 98613-35856, Iran. \\ ${ }^{2}$ Department of Plant Protection, Faculty of Agriculture, University of Tehran, Karaj, 31584, Iran. \\ Accepted 18 January, 2013

\begin{abstract}
Variation in transmission of ten clones of Schizaphis graminum (Rondani) originating from different regions of Iran was evaluated by transmitting an isolate of barley yellow dwarf virusPAV (BYDV-PAV) for which this species is normally an inefficient vector. After acquiring the virus, aphids of each clone-virus isolate combination were caged on 30 seedling using three forth instar nymphs per seedling. The inoculated and control plants were assayed by ELISA and assayed visually to determine the rate of transmission and the mean ELISA value for each treatment. A positive correlation was found between the rate of transmission and the mean absorbance value. Aphid clones differed in their efficiency of transmission of virus isolate. On the other hand, single clone transmitted virus isolate with varying efficiencies. The aphid clone of virus isolate origin transmitted virus isolate at the highest rate. In general, Shahre kord and Shahreza clones of aphids showed the highest efficiency of transmission and Delijan and Varamin clones had the lowest transmission efficiency between aphid clones.
\end{abstract}

Key words: Luteovirus, aphid clones, BYDV-PAV, transmission efficiency, Shizaphis graminum, Iran.

\section{INTRODUCTION}

Insects are vectors for a large number of plant and animal viruses and aphid are the most successful and numerous insect (Gray and Banerjee, 1999). Schizaphis graminum is an important insect pest of several grain crops and an efficient vector of cerealinfecting luteoviruses and poleroviruses (Porter et al., 1997; Puterka and Peters, 1995). Direct feeding injury, exacerbated by the induction of a phytotoxic response of the plant, can significantly reduce crop yield and value (Ryan et al., 1990). S. graminum is also a vector of several plant viruses, including the viruses that cause barley yellow dwarf disease (BYD). Barley yellow dwarf (BYD) is one of the

\footnotetext{
${ }^{*}$ Corresponding author. E-mail: mirshekar@hotmail.com.
}

most severe cereal diseases in the world (Lister and Ranieri, 1995). It is caused by different viruses belonging to the genera Luteovirus (BYDV-PAV and BYDV-MAV), Polerovirus (CYDV-RPV) or presently unassigned (taxa BYDV-RMV, BYDV-SGV, BYDVGPV) of the family Luteoviridae (D'Arcy and Mayo, 1997).

The viruses are all transmitted persistently by different aphid species living on Poaceae with a variable degree of vector specificity (Rochow, 1969). The viruses are vectored by at least 25 aphid species in a persistent (circulative) manner and are limited to the phloem tissues of infected plants (D'Arcy and Burnett, 1995).

Ingested virions are actively transported across gut epithelial cell cytoplasm in vesicles and released into the hemocoel. To be transmitted into a plant, the 
virions accumulate at the surface of the accessory salivary glands and are actively transported across the cells and deposited into the salivary duct. The virus does not replicate in any tissue of the aphid (Gray and Gildow, 2003). All of the virus species were initially differentiated based on the aphid vector that transmitted them most efficiently. The species RPV, RMV, MAV and SGV are readily transmitted by Rhopalosiphum padi (L.), $R$. maidis (Fitch), Sitobion (formely Macrosiphum) avenae (Fabricus), Schizaphis graminum (Rondani), respectively, while PAV is transmitted by both $R$. padi and $S$. avenae (Rochow, 1969; Johnston and Rochow, 1972; Rochow and Muller, 1971; Power et al., 1991). It is well documented that the various aphid species differ in their abilities to transmit the various variants of BYDV (Rochow, 1969; Rochow and Carmichael, 1979). Furthermore, populations within a species will differ in their ability to efficiently vector certain viruses. Intraspecific variation in vector capacity has been described for circulative plant viruses (Bencharki et al., 2000; Gray, 1999). However, little is known about intraspecific aphid variation. In USA, Rochow (1960) described clones of the greenbug $S$. graminum (Rondani) differing in their ability to transmit a BYDV-SGV isolate, and four biotypes (clones differing by biological characters) of the corn leaf aphid Rhopalosiphum maidis (Fitch) were reported to differ in their ability to transmit the AG-1 strain of BYDV (Saksena et al., 1964). Rochow and Eastop (1966) reported variation in the abilities of two morphologically different clones of Rhopalosiphum padi (L) to transmit BYDV-RMV.

Sadeghi et al. (1997 a, b) showed that two BYDVMAV isolates were efficiently transmitted by clones of the normally inefficient vector $R$. padi. More recently, similar results have been reported for the transmission of BYDV-RMV isolates by $R$. padi in North America (Lucio-Zavaleta et al., 2001). Virusaphid specificity seems to result from recognition between virions of a specific isolate and virus receptors in the accessory salivary glands of a particular aphid species (Gildow and Rochow, 1980; Gildow and Gray, 1993; Peiffer et al., 1997).

This vector specificity is not absolute because heteroencapsidation may enable a given aphid species to transmit a virus of which it is normally not a vector (Rochow and Pang, 1961; Rochow, 1975); also some isolates were reported to be transmitted by aphid species which are usually non vectors, as is the case for an Australian MAV serotype transmissible by $R$. padi (Lister and Sward, 1988), and for a Californian RPV serotype transmissible by both $S$. avenae and Schizaphis graminum (Rondani), and as by $R$. padi as well (Creamer and Falk, 1989); and finally within a given aphid species, clones could differ in their abilities to transmit viruses, as shown for both stylet-borne and circulative viruses (Sadeghi et al., 1997)

BYD was first reported in Iran in 1988, and BYDV-PAV was found to be the predominant serotype of the BYD causing viruses on both cultivated and non-cultivated cereals in all regions (Rastgou et al., 2004b). Among the aphids transmitting these viruses in Iran, $R$. padi was the predominant species followed by $S$. graminum, $R$. maidis and S. avenae (Khatabi et al., 2004b).

Aleosfoor et al. (2006) reported differences in transmission efficiency between seven clones of $R$. padi as a first intraspecific study on an aphid species in Iran. The objective of this study was to evaluate transmission efficiency of ten Schizaphis graminum population collected from different region of Iran in which aphid vector was inefficient vector.

This study is a pioneer work on determination of transmission efficiency in intraspecific clones which are ineffective vectors in Iran; also previous works involved only a small number of clones. The aim of the present work was to assess more widely transmission variations of a PAV isolate among a large sample of $S$. graminum clones collected in different parts of the Iran with different phenotypic characteristics. We have also sought to investigate the epidemiological role of PAV transmission by this species and finally, we have initiated a study to find contrasting variants for further investigations on the relationships between luteoviruses and putative virus receptors in their vectors.

\section{MATERIALS AND METHODS}

\section{Culture of virus isolate}

One BYDV-PAV isolate was used for the transmission experiments. The virus isolate used in this investigation was obtained from Center of Cereal Pathology at Agriculture College of Shiraz University in 2008 and causes severe yellowing to barley (cv. Zar-jo). The virus isolate was transferred to a groth chamber and maintained under controlled conditions $\left(20 \pm 2^{\circ} \mathrm{C}\right.$ and $\left.16 \mathrm{~L}: 8 \mathrm{D}\right)$ at the Agriculture College of University of Tehran. The isolates were maintained by repeated aphid transfers on 7-day old seedlings of barley Zar-jo cultivar at intervals of 5 to 6 weeks. The plants were inoculated with viruliferous $S$. graminum nymphs with a 3 day inoculation access period (IAP). After inoculation, plants were kept in a growth chamber at $20 \pm 2^{\circ} \mathrm{C}$ with $16 \mathrm{~h}$ illumination per day for symptoms to develop. Young leaves of the same age from infected Zar-jo plants, three weeks after the IAP, were used as a source of the virus in all experiments.

\section{Collecting and maintenance of aphid clones}

The aphid species used was $S$. graminum, the greenbug aphid. The aphid populations used in this work were collected during the cropping seasons of 2008 to 2009 in different regions of Iran and 10 aphid clones were prepared (Table 1). A few aphids were collected for each population. Colonies of 
Table 1. Percent infection and mean ELISA value of Barley (cv. Zar-Jo) seedlings inoculated with BYDV-PAV isolate and ten $S$. graminum clones. In each treatment, a total 30 seedling inoculated.

\begin{tabular}{lccc}
\hline \multirow{2}{*}{ Source of aphid } & \multicolumn{2}{c}{ Infection \% } & \multirow{2}{*}{ Mean ELISA Value \pm SD } \\
\cline { 2 - 3 } & By Symptom & By ELISA $\left(\mathbf{O D}_{\mathbf{4 5 0}}\right)$ & \\
\hline $\mathrm{Sg}-\mathrm{A}$ & 5.0 & 8.0 & $0.0696 \pm 0.023$ \\
$\mathrm{Sg}-\mathrm{B}$ & 5.0 & 6.0 & $0.0761 \pm 0.022$ \\
$\mathrm{Sg}-\mathrm{C}$ & 10.0 & 16.0 & $0.0878 \pm 0.016$ \\
$\mathrm{Sg}-\mathrm{D}$ & 10.0 & 13.0 & $0.0886 \pm 0.020$ \\
$\mathrm{Sg}-\mathrm{E}$ & 15.0 & 17.0 & $0.0905 \pm 0.025$ \\
$\mathrm{Sg}-\mathrm{F}$ & 15.0 & 19.0 & $0.0906 \pm 0.021$ \\
$\mathrm{Sg}-\mathrm{G}$ & 20.0 & 20.0 & $0.0916 \pm 0.017$ \\
$\mathrm{Sg}-\mathrm{H}$ & 25.0 & 21.0 & $0.1019 \pm 0.022$ \\
Sg-I & 36.0 & 35.0 & $0.1161 \pm 0.028$ \\
Sg-J & 40.0 & 42.0 & $0.1233 \pm 0.021$ \\
\hline
\end{tabular}

each population originated from a nymph born from a single viviparous aphid on filter paper. These colonies were grown on caged Zar-jo barley plants in a greenhouse compartment with precautions to prevent any accidental mixture between sub-populations and contamination by BYDV. Since each subpopulation originates from an individual aphid, it may be expected that its competence to transmit will not differ from its parent. For continuous maintenance of the subpopulations, one aphid adult was transferred to a new healthy Zar-Jo barley seedling every three weeks. All transmission studies were done with 2 to 3-day-old apterous adults caged separately on Zar-Jo barley seedlings. As mentioned, populations belonging ten different regions of Iran were reproduced separately and used in the experiments.

\section{Testing for virus-transmission efficiency}

In a first experiment, virus-free aphids of each population were removed from the rearing barley plants and given $12 \mathrm{~h}$ acquisition access period (AAP) on detached leaves from a barley plant infected with the PAV isolate studied. Aphids were then transferred with a fine brush to 30 barley test plants (1-leaf stage), by groups of 3 per plant and the plants were then individually caged with a cellophane bags for 5 day IAP. At the end of the IAP, plants were sprayed with the insecticide Primor and maintained in an insect-proof greenhouse. After a 15 day period of allowing virus multiplication in the plants, each plant was tested for virus content with a double antibody sandwich enzyme linked immunosorbent assay (DAS-ELISA) to assess percentages of infection for each clone. Disease symptoms were scored 4 weeks after inoculation. All plants were individually tested in DAS-ELISA. Results excluded tests where the source tissue had an absorbance value lower than three times those of the healthy ones. To determine the average difference from the control group, analysis of variance (ANOVA) in Minitab software and Duncan test in SPSS software was used.

\section{RESULTS}

Our study revealed that all 10 clones tested, transmitted PAV isolate but in different amount but in low percentage $(<15 \%)$ for most of them. However clones transmitted virus isolate in different efficiencies. Infection percentage by symptoms and by ELISA was evaluated. It varied from 5 to 40 and 6 to $42 \%$ respectively. The lowest absorbent rate and transmission percentage by ELISA corresponded to $\mathrm{Sg}-\mathrm{A}$ population (Table 1). Plants with the highest symptoms rates were observed in Sg-J population. A positive correlation was found between the rate of transmission and the mean absorbance value (Figure 1). Infection percent for clones Sg-J and Sg-I was 42 and 35 respectively, also Duncan test showed that these two clones are in same group and they transmitted at a significantly higher level than other clones. Infection for clones Sg-1 and Sg-2 were at 8 and $6 \%$ respectively. Duncan's range tested for these ones showed that they were in a same group and two clones transmitted virus isolate poorly $(<5 \%)$ (Table 2). Between 300 inoculated seedling tested, 204 seedlings by ELISA index $(\overline{\mathrm{X}}+3 \mathrm{SD})$ and 183 seedlings by symptoms were positive. Plants which were distinguished as infected based on symptoms also were infected by ELISA evaluation. The correlation between these indexes was 0.97.

Our results demonstrate that mean of absorbance value in ELISA had direct relation to geographical origin of viruses in which virus isolate transmitted highly with aphid population with same origin. Our results are correlated with other findings; as shown Shahre-kord population (Sg-J) transmitted virus serotype more effective than other populations; Duncan test revealed that $\mathrm{Sg}-\mathrm{I}$ and $\mathrm{Sg}-\mathrm{J}$ are in same group (Table 2) and transmitted virus serotype with significant difference and their mean absorbance value was 0.028 and 0.021 respectively. All aphid populations tested in the transmission efficiencies, were in four groups; Sg-A and Sg-B with 0.069 and 0.076 absorbance value were in the first group. ELISA absorbance value for $\mathrm{Sg}-\mathrm{C}, \mathrm{Sg}-\mathrm{D}, \mathrm{Sg}-\mathrm{E}, \mathrm{Sg}-\mathrm{F}$ 


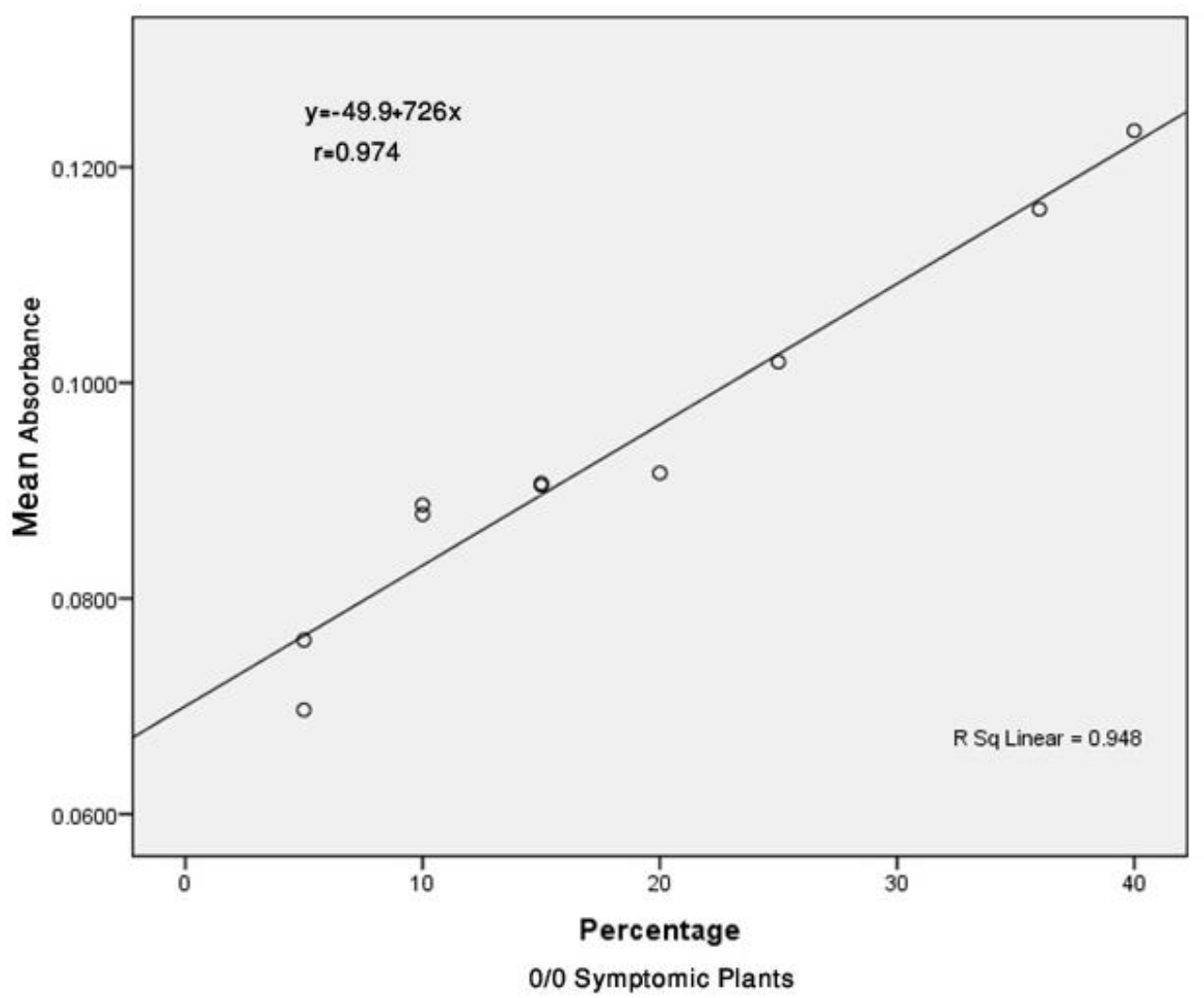

Figure 1. Correlation between mean ELISA value and \% symptoms Barley plants using BYDV-PAV isolates and ten $S$. graminum clones.

Table 2. Transmission efficiencies for BYD by each ten aphid clones.

\begin{tabular}{ll}
\hline Aphid clone & Mean \pm S.E. \\
\hline Group control & $0.05140 \pm .001^{\mathrm{a}}$ \\
Sg-A & $0.06967 \pm .002^{\mathrm{b}}$ \\
Sg-B & $0.07614 \pm .003^{\mathrm{b}}$ \\
Sg-C & $0.08780 \pm .004^{\mathrm{c}}$ \\
Sg-D & $0.08868 \pm .004^{\mathrm{c}}$ \\
Sg-E & $0.09050 \pm .004^{\mathrm{c}}$ \\
Sg-F & $0.09067 \pm .005^{\mathrm{c}}$ \\
Sg-G & $0.09163 \pm .005^{\mathrm{c}}$ \\
Sg-H & $0.10193 \pm .006^{\mathrm{d}}$ \\
Sg-I & $0.11610 \pm .007^{\mathrm{e}}$ \\
Sg-J & $0.12337 \pm .007^{\mathrm{e}}$ \\
\hline
\end{tabular}

${ }^{a}$ Means followed by different letters are significantly different according to Duncan's range test.

and Sg-G populations was $0.087,0.088,0.090$, 0.090 and 0.091 respectively and were in second group. The third group involved $\mathrm{Sg}-\mathrm{E}, \mathrm{Sg}-\mathrm{F}, \mathrm{Sg}-\mathrm{G}$ and $\mathrm{Sg}-\mathrm{H}$. Their ELISA absorbance values were $0.090,0.090,0.091$ and 0.101 respectively. Also Sg-I and Sg-J were in the forth group with 0.116 and 0.123 ELISA absorbance value.

\section{DISCUSSION}

BYDV is widespread in Iran. Among its serotypes, BYDV-PAV is the dominant serotype around the country (Afsharifar et al., 2004). Studies on this serotype showed that there is biological and molecular diversity among serotypes of BYDV-PAV 
(Dedryver et al., 2005; Tahan 2006). $R$. padi is known to be an efficient vector of virus (Rochow, 1969). Different reports about different dispersion of this virus in fields may support the hypothesis that another virus serotypes has a major role in dispersion of virus.

Further complicating the epidemiology of BYDVPAV is the evidence that $S$. graminum may be a more efficient vector of BYDV-PAV if the plant was originally inoculated by $S$. graminum (Rochow, 1961; Rochow, 1963).

Clones originated from regions that aphid have holocyclic life transmitted significantly better than others. Our result is similar to those of Sadeghi et al. (1997) that reported that European clones of $R$. padi transmitted BYDV-MAV significantly better than other clones in which they have holocyclic life.

There are only few reports of intraspecific variations in virus transmission by aphids and most of them compare a very small number of clones. Those on BYD-viruses mainly concern quantitative variations in transmission percentages of a given serotype by its main vector (Rochow, 1960; Saksena et al., 1964; Guo et al., 1996; Sadeghi et al., 1997). Only Rochow and Eastop (1966) and more recently Guo (1995) reported transmission studies on serotypes for which aphid species tested are usually inefficient vectors, that is variations in transmission abilities of respectively (i) two $R$. padi clones for RMV, normally transmitted by $R$. maidis and (ii) two clones of $R$. padi for MAV transmission. We compared for the first time PAV transmission by numerous $S$. graminum clones collected from diverse geographical areas; our results show there are overall differences among isolate for transmission.

These results, which fit well with some field records and PAV transmission by $S$. graminum may have some epidemiological consequences. In France, MAV contaminations of barley fields are commonly observed in autumn, although the normal vectors of this virus ( $S$. avenae and $M$. dirhodum) are absent or very scarce (Leclercq-Le Quillec, 1992). Most of the plants are infected by SGV and PAV, indicating that heterologus encapsidation could play a role in PAV transmission by $S$. graminum.

This is a direct proof that MAV transmission by $R$. padi can occur in field conditions, that all $S$. graminum clones tested transmitted at least PAV isolate in the laboratory, and that two clones of 10 were rather efficient vectors, which means that outdoor PAV transmissions by $S$. graminum could be frequent and epidemiologically important, at least when $S$. graminum populations contains many $\mathrm{Sg}-\mathrm{I}$ And Sg-G.

In the aphid, the virus must cross from the hindgut into the hemocoel, then survive in the hemocoel, join the salivary glands and penetrate into the accessory salivary glands to be egested. Van den Heuvel et al. (1994) have demonstrated that symbionin, a GroEL homologous protein synthesized by endosymbiotic bacteria (genus Buchnera) and secreted into the aphid hemolymph, is essential for efficient luteovirus transmission. Possibly, symbionin of the inefficient aphid $\mathrm{Sg}-\mathrm{A}$ and $\mathrm{Sg}-\mathrm{B}$ is released at low concentrations or has low binding affinity for the virus. The later possibility is indirectly supported by the recent findings of Van den Heuvel et al. (1997), who showed that symbionin from different aphid species bound in vitro with different affinities to Luteoviridae. Also, it is likely that several barriers and therefore several genetic loci are responsible for vector competence (Dedryver, 2005).

The transmission efficiency may have been associated also to the retention and to natural losses of virus content in aphids during the feeding process. The recognition and understanding of the factors involved in the host-virus-vector interaction may lead to efficient control of those PAV isolates which provoke severe disease and aid in the breeding for resistant cultivars. (Lucio-Zavaleta et al., 2001).

\section{REFERENCES}

Bencharki B, Yamani ME, Zaoui D (2000). Assessment of transmission ability of barley yellow dwarf virus-PAV isolates by different populations of Rhopalosiphum padi and Sitobion avenae. Eur. J. Plant Pathol. 106:455-464.

D'Arcy CJ, Burnett PA (1995). Barley yellow dwarf virus: A brief introduction. In: D'Arcy CJ and Burnett PA (eds.): Barley Yellow Dwarf: 40 Years of Progress. APS Press, St. Paul, Minnesota, USA, pp. 1-5.

D'Arcy CJ, Mayo M (1997). Proposal for changes in luteovirus taxonomy and nomenclature. Archiv. Virol. 142:1285-1287.

Dedryver CA, Riault G, Tanguy S, Le Gallic JF, Trottet M, Jacquot $E$ (2005). Intra-specific variation and inheritance of BYDV-PAV transmission in the aphid Sitobion avenae. Eur. J. Plant Pathol. 111:341-354.

Gildow FE (1993). Evidence for receptor-mediated endocytosis regulating luteovirus acquisition by aphids. Phytopathology 83:270-277.

Gildow FE, Gray SM (1993). The aphid salivary gland basal lamina as a selective barrier associated with vector specific transmission of barley yellow dwarf luteoviruses. Phytopathology 83:12931302.

Gildow FE, Rochow WF (1980). Role of accessory salivary glands in aphid transmission of barley yellow dwarf luteovirus. Virology 104:97-108.

Gray SM (1999). Intraspecific variability of luteovirus transmission within aphid vector populations. In: Smith, H. G. and Barker, $\mathrm{H}$. (eds.): The Luteoviridae. CABI Publishing, Wallingford, UK, pp. 119-123.

Gray SM, Banerjee N (1999). Mechanisms of arthropod transmission of plant and animal viruses. Microbiol. Mol. Biol. R. 63:128-148.

Gray SM, Chapin JW, Smith DM, Banerjee N, Thomas JS (1998). Barley yellow dwarf luteoviruses and their predominant aphid vectors in winter wheat grown in South Carolina. Plant Dis. 82:1328-1333.

Gray SM, Gildow FE (2003). Luteovirus-aphid interactions. Annu. Rev. Phytopathol. 41:539-566.

Gray SM, Power AG, Smith DM, Seaman AJ, Altman NS (1991). 
Aphid transmission of barley yellow dwarf virus: Acquisition access period and virus concentration requirements. Phytopathology 81:539-545.

Gray SM, Smith DM, Barbierri L, Burd J (2002). Virus transmission phenotype is correlated with host adaptation among genetically diverse populations of the aphid Schizaphis graminum. Phytopathology 92:970-975.

Johnston RA, Rochow WF (1972). An isolate of barley yellow dwarf virus transmitted specifically by Schizaphis graminum. Phytopathology 62:921-925.

Khatabi B, Rastgou M, Izadpanah K (2004a). Purification and antiserum preparation of Iranian isolate of cereal yellow dwarf virus-RPV. Proc. 16th. Iran Plant Prot. Tabriz, Iran p. 82.

Khatabi B, Rastgou M, Masoumi M, Afsharifar AR, Izadpanah K (2004b). Efficiency of cereal aphids in BYDV-MAV and CYDVRPV transmission. Proc. 16th. Iran Plant Prot. Tabriz, Iran p. 82.

Leclercq-Le Quillec F, Tanguy S, Dedryver CA (1995). Aerial flow of barley yellow dwarf viruses and of their vectors in western France. Ann. Appl. Biol. 126:75-90.

Lister RM, Ranieri R (1995). Distribution and economic importance of barley yellow dwarf. In: D'Arcy, C. J. and Burnett, P. A. (eds.): Barley Yellow Dwarf: 40 years of Progress. The American Phytopathological Society, St Paul, Minnesota, USA, pp. 29-54.

Lucio-Zavaleta E, Smith DM, Gray SM (2001). Variation in transmission efficiency among barley yellow dwarf virus -RMV isolates and clones of the normally inefficient aphid vector, Rhopalosiphum padi. Phytopathology 91:792-796.

Peiffer ML, Gildow FE, Gray SM (1997). Two distinct mechanisms regulate luteovirus transmission efficiency and specificity at the aphid salivary gland. J. Gen. Virol. 78:495-503.

Porter DR, Burd JD, Shufran KA, Webster JA, Teetes GL (1997). Greenbug (Homoptera: Aphididae) biotypes: Selected by resistant cultivars or preadapted opportunists?. J. Econ. Entomol. 90:1055-1065.

Power AG, Gray SM (1995). Aphid transmission of barley yellow dwarf viruses: Interactions between viruses, vectors, and host plants. In: Barley Yellow Dwarf: 40 Years of Progress (eds.): D'Arcy, C. J. and Burnett, P. A. Am. Phytopathol. Soc. St. Paul, MN. USA, pp. 259-291.

Puterka GJ, Peters DC (1995). Genetics of greenbug (Homoptera: Aphididae) virulence to resistance in sorghum. J. Econ. Entomol. 88:421-429

Rastgou M, Khatabi B, Kvarnheden A, Izadpanah K (2005). Relationships of Barley yellow dwarf virus-PAV and Cereal yellow dwarf virus-RPV from Iran with viruses of the family Luteoviridae. Eur. J. Plant Pathol. 113:321-326.

Rochow WF (1960). Specialization among greenbugs in the transmission of barley dwarf virus. Phytopathol. 50:881-884.

Rochow WF (1961). A strain of barley yellow dwarf virus transmitted specifically by the corn leaf aphid. Phytopathology $51: 809-810$.
Rochow WF (1963). Variation within and among aphid vectors of plant viruses. Ann. N. Y. Acad. Sci. 105:713-729.

Rochow WF (1969). Biological properties of four isolates of barley yellow dwarf virus. Phytopathology 59:1580-1589.

Rochow WF, Carmichael LE (1979). Specificity among barley yellowdwarf virus in enzyme immunosorbent assays. Virology 95:415-520.

Rochow WF, Eastop VF (1966). Variation within Rhopalosiphum padi and transmission of barley yellow dwarf virus by clones of four aphid species. Virology 30:286-296.

Rochow WF, Muller I (1971). A fifth variant of barley yellow dwarf virus in New York. Plant Dis. 55:874-877.

Ryan JD, Morgham AT, Richardson PE, Johson RC, Mort AJ, Eikenbary RD (1990). Greenbugs and wheat: A model system for the study of phytotoxic homoptera. In: Campbell, R. K. and Eikenbary, R. D. (eds.): Aphid-Plant Genotype Interactions. Elsevier Science, Amsterdam. pp. 171-186.

Sadeghi E, Dedryver CA, Gauthier JP (1997a). Role of acquisition and inoculation time in the expression of clonal variation for BYDV-PAV transmission in the aphid species Rhopalosiphum padi. Plant Pathol. 46:502-508.

Sadeghi E, Dedryver CA, Riault G, Gauthier JP. (1997b). Variation in transmission of two BYDV-MAV isolates by multiple clones of Rhopalosiphum padi L. Eur. Plant Pathol. 103:515-519.

Sadeghi E, Dedryver CA, Tanguy S, Riault G (1995). Intraspecific variations for transmission of BYDV-PAV and -MAV isolates by the aphids Sitobion avenae and Rhopalosiphum padi. Agronomie. 15:504-505.

Saksena KN, Singh SR, Sill WH (1964). Transmission of barley yellow dwarf virus by four biotypes of the corn leaf aphid, Rhopalosiphum maidis. J. Econ. Entomol. 57: 569-571.

Van den Heuvel JFJM, Verbeek M, van der Wilk F (1994). Endosymbiotic bacteria associated with circulative of potato leafroll virus by Myzus percisae. J Gen. Virol. 75:2559-2565.

Van den Heuvel JFJM, Bruy`ere A, Hohenhout S A, Ziegler-Graff V, Brault V, Verbeek M, van der Wilk F, Richards K (1997). The $\mathrm{N}$-terminal region of the luteovirus read through domain determines virus binding to Buchnera GroEL and is essential for virus persistence in the aphid. J. Virol. 71:7258-7265. 